\title{
Intakes of fruits, vegetables and carbohydrate and the risk of CVD
}

Kaumudi J Joshipura ${ }^{1,2,3, *}$, Hsin-Chia Hung ${ }^{4}$, Tricia $Y \mathrm{Li}^{5}$, Frank B Hu${ }^{2,5}$, Eric B Rimm ${ }^{2,5}$, Meir J Stampfer ${ }^{2,5,6}$, Graham Colditz ${ }^{2,7,8}$ and Walter C Willett ${ }^{2,5,6}$ ${ }^{1}$ Center for Clinical Research and Health Promotion, University of Puerto Rico, Medical Sciences Campus, School of Dentistry Office A-107, PO Box 365067, San Juan, Puerto Rico PR00936: 'Department of Epidemiology, Harvard School of Public Health, Boston, MA, USA: ${ }^{3}$ Department of Oral Health Policy and Epidemiology, Harvard School of Dental Medicine, Boston, MA, USA: ${ }^{4}$ Graduate Institute of Health Care, Meiho Institute of Technology, PingTong, Taiwan: ${ }^{5}$ Department of Nutrition, Harvard School of Public Health, Boston, MA, USA: ${ }^{6}$ Channing Laboratory, Department of Medicine, Brigham and Women's Hospital and Harvard Medical School, Boston, MA, USA: "Washington University School of Medicine, St. Louis, MO, USA:

${ }^{8}$ Alvin J Siteman Cancer Center, St Louis, MO, USA

Submitted 3 April 2007: Accepted 2 February 2008: First published online 15 April 2008

\begin{abstract}
Background: Low-carbohydrate diets could lead to reduced fruit and vegetable intake, which may be protective against CVD. The role of carbohydrate intake in modifying the association between fruits and vegetables and CVD has not been evaluated.

Objective: To evaluate whether carbohydrate intake affects the association between fruits and vegetables and CVD.

Design: We included participants from two large prospective studies, the Nurses' Health Study (NHS) and the Health Professionals' Follow-Up Study (HPFS). We followed 70870 eligible NHS females for 16 years and 38918 eligible HPFS males for 14 years. Diet was assessed from an FFQ updated every 4 years. Our primary outcome was ischaemic CVD (fatal and non-fatal myocardial infarction and ischaemic stroke). We used Cox proportional hazards models to evaluate the relationship between fruits and vegetables and ischaemic CVD within groups with low, moderate or high carbohydrate intake.

Results: Fruit intake was strongly related with carbohydrate intake, but vegetables showed a very small correlation. Vegetable intake showed stronger associations with ischaemic CVD among the low carbohydrate group (multivariate risk ratio $(\mathrm{RR})=0.82$ for an increment of 3 servings $/ \mathrm{d}$; 95\% CI 0.68, 0.99); green leafy vegetables and carotene-rich fruits and vegetables followed a similar pattern. Total fruit intake was associated with a lower risk of ischaemic CVD only among participants with moderate carbohydrate intake $(\mathrm{RR}=0 \cdot 81$ comparing extreme quintiles; 95\% CI 0.70, 0.94).

Conclusions: Total vegetables, green leafy vegetables and carotene-rich fruits and vegetables showed stronger associations with ischaemic CVD among the low carbohydrate group. No consistent trends were observed for fruit intake.
\end{abstract}

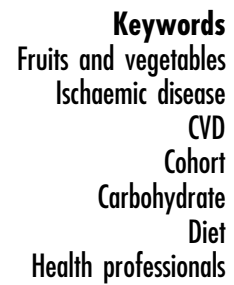

In recent years, awareness of obesity and its impact on morbidity has increased and several diets are widely followed for weight loss. Some of these diets, such as Atkins and South Beach, promote very low intake of carbohydrate $^{(1)}$, and many products are advertised as 'low carb' or 'no carb'. These trends in reduced carbohydrate intake could potentially lead to decreased fruit and vegetable intake. In our prospective studies, high intake of fruits and vegetables was related to lower risk of ischaemic stroke ${ }^{(2)}, \mathrm{CHD}^{(3)}$ and total $\mathrm{CVD}^{(4)}$; an increment of
5 servings of fruits or vegetables per day was associated with $12 \%$ lower risk of CVD after controlling for standard cardiovascular risk factors ${ }^{(5)}$. Also, nutrients contained in fruits and vegetables, such as dietary fibre, potassium and antioxidants, were associated with reduced risk of CVD $^{(5-9)}$.

Although previous studies have evaluated the association between fruits and vegetables and CVD and between carbohydrates and CVD, the combination of fruits and vegetables and carbohydrate intake or the effect of fruit 
and vegetable intake on CVD in a group with low carbohydrate intake has not been evaluated. Hence, our primary objective was to evaluate prospectively the association between intakes of total and specific fruits and vegetables and incidence of CVD among people with low carbohydrate intake.

\section{Subjects and methods}

\section{Study populations}

The populations for the present analysis consist of the same prospective cohorts reported above, the Nurses' Health Study (NHS) ${ }^{(10)}$ and the Health Professionals' Follow-Up Study (HPFS) ${ }^{(11)}$. The two studies have similar designs. The NHS started in 1976 when 121700 female registered nurses, aged 30 to 55 years, were recruited; diet was first assessed in 1980. The HPFS population was recruited in 1986 and consisted of 51529 male health professionals including dentists, veterinarians, pharmacists, optometrists, osteopaths and podiatrists aged 40-75 years. Mailed questionnaires on medical history, health behaviours, and the occurrence of cardiovascular and other outcomes are completed every 2 years by the participants. Since the 1980 NHS questionnaire only had a partial listing of fruits and vegetables, we used 1984 as the baseline in NHS for the present report.

We excluded participants with incomplete or implausible dietary assessments (as described below) or with cancer, diabetes or CVD that was reported before the baseline dietary assessment. We followed 70870 eligible women over the subsequent 16 years of follow-up and 38918 eligible men over 14 years of follow-up to assess incidence of CVD. Participants who died or had a CVD event during the follow-up period were excluded from subsequent follow-up. The study was approved by our Institutional Review Board.

\section{Dietary assessment}

The 1984 NHS questionnaire had 126 items including fifteen fruit items and twenty-eight vegetable items plus potatoes; similar questionnaires were repeated in NHS in 1986, 1990, 1994 and 1998 and in the HPFS in 1986, 1990, 1994 and 1998. We excluded participants who left seventy or more dietary questions blank or with implausible values for total energy intake (outside the range of $2 \cdot 09-14.64 \mathrm{MJ} / \mathrm{d} \quad(500-3500 \mathrm{kcal} / \mathrm{d})$ for women and $3 \cdot 35-17 \cdot 57 \mathrm{MJ} / \mathrm{d}(800-4200 \mathrm{kcal} / \mathrm{d})$ for men).

Participants reported their average frequency of intake of the specified standard serving/portion size for each food over the past year. Detailed descriptions of the FFQ for both men and women have been published previously $^{(11-13)}$. The average daily intakes of individual fruit and vegetable items were combined to compute total and composite fruit and vegetable intakes for each participant as in our previous reports ${ }^{(2,14)}$. We did not include potatoes, tofu and soyabeans, dried beans and lentils, or condiments such as chilli sauce and garlic, that had very small portion sizes, in computing total vegetable intake. High-carotene fruits and vegetables included cantaloupe, watermelon, grapefruit, broccoli, carrots, mixed vegetables, yellow squash, yams or sweet potatoes, cooked or raw spinach, kale, mustard or chard greens, romaine or leaf lettuce, tomatoes, tomato juice or sauce. Vitamin C-rich fruits and vegetables included foods containing over $30 \mathrm{mg}$ of vitamin $\mathrm{C}$ per serving. When aggregating items to compute the composite items, we assumed that individuals with food items with missing data did not consume that item ${ }^{(15)}$. We used cumulative averages to combine the diet over different questionnaires; the cumulative average dampens within-person variation and has lower measurement error than a single FFQ measurement ${ }^{(16)}$.

\section{Assessment of cardiovascular endpoints}

The primary outcome was ischaemic CVD, which included fatal CHD or non-fatal myocardial infarction and fatal or non-fatal ischaemic stroke (excluding haemorrhagic strokes and strokes of unknown type). We sought to review medical records for all reports of CVD for the time period after return of the 1984 questionnaire (women) and 1986 questionnaire (men) but before 1 June 2000 (women) and 1 January 2000 (men). Ischaemic stroke and CHD were defined and verified as in our earlier publications ${ }^{(2,3)}$. We included all confirmed and probable cases of fatal and non-fatal ischaemic stroke and CHD in our analyses because results were very similar after excluding probable cases.

\section{Statistical analyses}

We defined three groups based on the univariate distribution of percentage of energy from carbohydrate to obtain reasonable power in each of the three groups (low: <40\%, moderate: >40-55\%, high: $>55 \%$ ). We used Cox proportional hazards regression analysis to assess whether a high intake of total or specific fruits and vegetables was associated with reduced risk of ischaemic CVD among the three carbohydrate intake groups. Persontime for each participant was calculated from the date of return of the 1984 questionnaire in the NHS or the 1986 questionnaire in the HPFS to the earlier of the date of first CVD event, death or the cut-off date. Each participant contributed only one endpoint and the cohort at risk for each 2-year follow-up period included only those who remained free from reported CVD at the beginning of each follow-up period. We documented 2040 incident cases of ischaemic CVD among men and 1852 new cases among women. The analyses were performed separately in each cohort due to differences in gender and the questionnaires in the two cohorts. For the main analyses, to obtain overall estimates for both genders and increased power, we combined results from the two cohorts using the pooling methods proposed by DerSimonian and 
Laird $^{(17)}$. This approach was selected to achieve better control of confounding.

In the categorical analyses, the lowest quintile of intake formed the reference category. Linear trends in CVD risk were assessed by using the median value of intake for each decile of the composite item as a continuous variable, to minimize the influence of outliers. We scaled the increment for items with greater intake. Hence, the relative risk for the continuous measures indicates the change in risk associated with an average increment of 5 servings/d (total fruits and vegetables), 3 servings/d (total fruits or total vegetables) or 1 serving/d (other composite items) of the standard portion size. Analyses were adjusted for standard CVD risk factors: age (5-year categories); smoking (never, former, current: 1-14, 15-24, $>25$ cigarettes/d); alcohol (five categories); incident diabetes; family history of myocardial infarction (positive if either the mother or father had CHD at age 65 years or less in NHS or before age of 60 years in HPFS); BMI (five categories); multivitamin supplement use; vitamin E use; aspirin use; physical activity (quintiles); reported hypertension and hypercholesterolaemia; and time period. We also controlled for total energy intake and intake of whole grains (quintiles) ${ }^{(18)}$. We checked correlations among the dietary variables and accordingly decided to include whole grains but not dietary or cereal fibre as confounders since these were highly correlated with each other. Additionally, among women we controlled for menopause status and postmenopausal hormone use.

We updated information on diet and CVD risk factors over time to better represent long-term patterns ${ }^{(16,19)}$ using the 1984-1998 questionnaires in NHS and the 1986-1998 questionnaires in HPFS. For each 2-year follow-up period in which events were reported, we computed intake for each composite item as a cumulative average of intake from all available FFQ up to the start of the follow-up period. Since intermediate endpoints may influence diet, for participants who experienced angina, coronary artery bypass graft, angioplasty, hypercholesterolaemia, hypertension or diabetes we stopped updating diet at the beginning of the interval in which they had the outcome ${ }^{(16,19)}$. We updated the carbohydrate stratification variable after each dietary questionnaire, so that participants could contribute person-time to different strata at different time points.

In additional analyses, we created mutually exclusive groups of (i) low carbohydrate, high total fruit and vegetable intake, (ii) low carbohydrate, low fruit and vegetable intake, (iii) high carbohydrate, low fruit and vegetable intake and (iv) high carbohydrate, high fruit and vegetable intake. We evaluated the relative risks for the first three groups and total CVD, using the last group as the reference. For these analyses high carbohydrate was considered as $>50 \%$ energy from carbohydrates and high fruit and vegetable intake was considered as $>5$ servings/d. All analyses were conducted using
Statistical Analysis Systems statistical software package version $9 \cdot 1 \cdot 2$ (SAS Institute, Cary, NC, USA). The results were evaluated at the 0.05 level of statistical significance.

\section{Results}

\section{Descriptive analysis}

The low carbohydrate group generally showed less healthy habits (Table 1). Among men, there was a higher proportion of smokers (15\%) in the low carbohydrate group compared with the middle (7\%) and high (3\%) carbohydrate groups. Similarly among women, there were $26 \%$ of smokers in the low carbohydrate group compared with $13 \%$ in the moderate and $7 \%$ in the high carbohydrate groups. Men and women in the high carbohydrate group had higher physical activity than men and women the low carbohydrate group (42 v. 32 MET-h in men and $23 v$. 16 MET-h in women). Multivitamin supplement use was higher among those with high carbohydrate intake than in those with low carbohydrate intake. History of hypercholesterolaemia was higher among the high carbohydrate group.

Fruit intake was strongly associated with carbohydrate intake (correlation coefficient, $r$, of 0.43 in NHS and 0.50 in HPFS) but vegetables showed only a small correlation with carbohydrate intake $(r=0.06$ in NHS and 0.15 in HPFS). Total fruit and vegetable intake was $7 \cdot 6$ servings/d among men in the high carbohydrate group compared with 4.4 servings/d for men in the low carbohydrate group; among women the intake was 6.9 servings/d in the high carbohydrate group compared with $4 \cdot 1$ servings/d in the low carbohydrate group. Carbohydrate intake was correlated with dietary folate, vitamin $\mathrm{C}$ and potassium; correlation coefficients ranged from 0.29 to $0 \cdot 44$. The intakes of whole grains, dietary fibre, folate, potassium and vitamin C (from food or overall) were higher among the high carbohydrate group, whereas saturated fat consumption was lower in the high carbohydrate group. Total energy intake was related to fruit and vegetable intake $(r=0.45$ in HPFS and 0.50 in NHS) but not to intake of whole grains.

\section{Multivariate analyses}

Table 2 shows the overall results comparing extreme quintiles and testing for trends relating fruits and vegetables and ischaemic CVD separately within the low, moderate and high carbohydrate groups. Total fruits and vegetables showed a small non-significant inverse association among men and women with low energy-adjusted carbohydrate intake, with a pooled relative risk (RR) for an increment of 5 servings/d of $0 \cdot 81$ (95\% CI $0 \cdot 65,1 \cdot 01)$ and $P$ for trend of $0 \cdot 06$. When comparing the extreme quintiles of fruits and vegetables, a small insignificant association was also seen in the low carbohydrate group $(\mathrm{RR}=0 \cdot 73 ; 95 \%$ CI $0 \cdot 51,1 \cdot 04)$. 
Table 1 Description of age-standardized* cardiovascular risk factors in 1994 by category of carbohydrate intake: the Health Professionals' Follow-Up Study (HPFS) and the Nurses' Health Study (NHS)

\begin{tabular}{|c|c|c|c|c|c|c|}
\hline & \multicolumn{3}{|c|}{ HPFS } & \multicolumn{3}{|c|}{ NHS } \\
\hline & \multicolumn{3}{|c|}{$\begin{array}{l}\text { Percentage of energy from } \\
\text { carbohydrate intake }\end{array}$} & \multicolumn{3}{|c|}{$\begin{array}{l}\text { Percentage of energy from } \\
\text { carbohydrate intake }\end{array}$} \\
\hline & $\begin{array}{l}\text { Low } \\
(<40 \%)\end{array}$ & $\begin{array}{c}\text { Middle } \\
(>40-55 \%)\end{array}$ & $\begin{array}{l}\text { High } \\
(>55 \%)\end{array}$ & $\begin{array}{l}\text { Low } \\
(<40 \%)\end{array}$ & $\begin{array}{c}\text { Middle } \\
(>40-55 \%)\end{array}$ & $\begin{array}{c}\text { High } \\
(>55 \%)\end{array}$ \\
\hline Age (years) & $60 \cdot 7$ & $61 \cdot 1$ & $61 \cdot 8$ & $58 \cdot 8$ & $59 \cdot 5$ & $60 \cdot 9$ \\
\hline Current smokers (\%) & $14 \cdot 6$ & $6 \cdot 5$ & $2 \cdot 5$ & $25 \cdot 9$ & $13 \cdot 4$ & $7 \cdot 2$ \\
\hline Physical activity (ME'T-h)† & $31 \cdot 5$ & $35 \cdot 6$ & $42 \cdot 0$ & $16 \cdot 1$ & $18 \cdot 9$ & $22 \cdot 5$ \\
\hline BMI $\left(\mathrm{kg} / \mathrm{m}^{2}\right)$ & $26 \cdot 7$ & $26 \cdot 1$ & $25 \cdot 1$ & $26 \cdot 5$ & $26 \cdot 5$ & $25 \cdot 6$ \\
\hline \multicolumn{7}{|l|}{ History at baseline } \\
\hline Hypertension (\%) & $31 \cdot 6$ & $29 \cdot 0$ & $28 \cdot 0$ & $33 \cdot 1$ & $32 \cdot 6$ & $33 \cdot 2$ \\
\hline High cholesterol (\%) & $34 \cdot 6$ & $37 \cdot 4$ & $41 \cdot 2$ & $40 \cdot 2$ & $43 \cdot 9$ & $51 \cdot 0$ \\
\hline Parents' CHD history (\%)‡ & $30 \cdot 6$ & $30 \cdot 2$ & $33 \cdot 2$ & $19 \cdot 5$ & $19 \cdot 5$ & $19 \cdot 6$ \\
\hline Current oestrogen replacement $(\%) \S$ & - & - & - & $58 \cdot 8$ & $50 \cdot 7$ & $59 \cdot 6$ \\
\hline Multivitamin supplement use (\%) & $44 \cdot 9$ & $48 \cdot 0$ & $55 \cdot 2$ & $42 \cdot 0$ & $45 \cdot 8$ & $51 \cdot 0$ \\
\hline Total fruits and vegetables (servings/d) & $4 \cdot 36$ & $5 \cdot 76$ & $7 \cdot 56$ & $4 \cdot 09$ & $5 \cdot 41$ & $6 \cdot 86$ \\
\hline Total fruits (servings/d) & $1 \cdot 41$ & $2 \cdot 35$ & $3 \cdot 58$ & $1 \cdot 15$ & 2.04 & $3 \cdot 05$ \\
\hline Total vegetables (servings/d) & 2.95 & $3 \cdot 41$ & $3 \cdot 98$ & $2 \cdot 94$ & $3 \cdot 38$ & $3 \cdot 81$ \\
\hline Total energy (MJ) & $8 \cdot 51$ & $8 \cdot 65$ & $8 \cdot 15$ & $6 \cdot 91$ & $7 \cdot 31$ & $7 \cdot 25$ \\
\hline Total energy (kcal) & 2033 & 2067 & 1947 & 1651 & 1747 & 1733 \\
\hline Total carbohydrate (g) & 178 & 241 & 304 & 143 & 196 & 244 \\
\hline Whole grains $(\mathrm{g})$ & $16 \cdot 4$ & $26 \cdot 8$ & $40 \cdot 2$ & $11 \cdot 3$ & $18 \cdot 8$ & $28 \cdot 0$ \\
\hline Saturated fat (g) & $28 \cdot 5$ & $23 \cdot 6$ & $16 \cdot 9$ & $23 \cdot 0$ & $19 \cdot 0$ & $13 \cdot 6$ \\
\hline Dietary fibre (g) & $15 \cdot 9$ & $21 \cdot 0$ & $27 \cdot 9$ & $13 \cdot 5$ & $17 \cdot 3$ & $22 \cdot 0$ \\
\hline Cereal fibre (g) & $4 \cdot 53$ & $6 \cdot 95$ & $9 \cdot 47$ & $3 \cdot 49$ & $5 \cdot 26$ & $7 \cdot 02$ \\
\hline Folate from food $(\mu \mathrm{g}) \|$ & 277 & 337 & 408 & 235 & 287 & 340 \\
\hline Total folate $(\mu \mathrm{g})$ & 440 & 501 & 613 & 371 & 426 & 505 \\
\hline Vitamin C from food (mg) & 114 & 153 & 206 & 102 & 135 & 173 \\
\hline Vitamin $\mathrm{C}(\mathrm{mg}) \|$ & 373 & 425 & 574 & 303 & 334 & 424 \\
\hline Potassium from food (mg)\| & 3037 & 3339 & 3709 & 2670 & 2988 & 3274 \\
\hline Potassium (mg) & 3048 & 3349 & 3722 & 2720 & 3029 & 3320 \\
\hline
\end{tabular}

*Standardized for age (except for age itself) to the cohort age distribution (NHS or HPFS); values are means, unless otherwise specified.

$+\mathrm{MET}-\mathrm{h}=$ sum of the average time/week spent in each activity $\times$ MET value of each activity, where

MET (metabolic equivalent energy task) value $=\frac{\text { energy need } / \mathrm{kg} \text { body weight } / \text { hour of activity }}{\text { energy need } / \mathrm{kg} \text { body weight } / \text { hour at rest }}$.

$\ddagger$ The mother or father had CHD at age 65 years or less in NHS or before age of 60 years in HPFS.

§Only among postmenopausal women.

IExcludes intake from supplements.

- Includes intake from food and/or supplements.

Total fruit showed the strongest inverse association among the moderate carbohydrate group when comparing extreme quintiles ( $\mathrm{RR}=0 \cdot 81 ; 95 \%$ CI $0 \cdot 70,0 \cdot 94)$. No significant linear association was found in any of the carbohydrate intake groups: for the low carbohydrate group the RR was $0 \cdot 88(95 \%$ CI $0 \cdot 66,1 \cdot 18$; $P$ for trend $=0 \cdot 42)$; for the moderate group the RR was $0 \cdot 90$ (95\% CI $0 \cdot 80,1 \cdot 01 ; P$ for trend $=0.07)$; for the high carbohydrate group the RR was $0.93(95 \%$ CI $0.76,1 \cdot 13 ; P$ for trend $=0 \cdot 46)$. The association for total citrus fruit and citrus fruit juice consumption was not significant and not substantially different across the three carbohydrate groups.

The linear trend was significant for total vegetables in the low carbohydrate group, with a pooled RR for 3 servings/d of 0.82 (95\% CI 0.68, 0.99; $P$ for trend $=0.04)$. The RR was 0.97 in the moderate $(95 \%$ CI $0 \cdot 88,1 \cdot 06)$ and 0.99 (95\% CI $0 \cdot 84,1 \cdot 17)$ in the high intake group. Green leafy vegetables showed a significant linear association in the low $(\mathrm{RR}=0 \cdot 84 ; 95 \%$ CI $0 \cdot 71,0 \cdot 99 ; P$ for trend $=0 \cdot 04)$ and moderate group (RR $=0.90 ; 95 \% \mathrm{CI} 0 \cdot 82,0 \cdot 99 ; P$ for trend $=0 \cdot 03$, with the strongest inverse association found when comparing extreme quintiles in the low carbohydrate group $(\mathrm{RR}=0 \cdot 76 ; 95 \% \mathrm{CI} 0 \cdot 60,0 \cdot 96)$. There was no trend between green leafy vegetable intake and ischaemic CVD in the high carbohydrate group $(\mathrm{RR}=$ $0 \cdot 98 ; 95 \%$ CI $0 \cdot 83,1 \cdot 17)$. Carotene-rich fruits and vegetables also showed a stronger association in the low carbohydrate group (RR for 1 serving/d = 0.90; 95\% CI $0 \cdot 81,0.99 ; \quad P$ for trend $=0 \cdot 04)$. All associations were generally attenuated among the multivitamin supplement users (data not shown in the tables).

We examined the joint association between fruit and vegetables and carbohydrate intake with ischaemic CVD. Compared with the high fruit and vegetable ( $>5$ servings/ d), high carbohydrate ( $>50 \%$ energy from carbohydrates) intake group, the low fruit and vegetable and high carbohydrate group showed an increased risk for ischaemic CVD in men (RR $=1 \cdot 21 ; 95 \%$ CI 1.02, 1.42) but not in women $(\mathrm{RR}=1 \cdot 05 ; 95 \% \mathrm{CI} 0 \cdot 89,1 \cdot 26)$, and the low fruit and vegetable and low carbohydrate group showed a very small association for ischaemic CVD in men $(\mathrm{RR}=1 \cdot 15 ; 95 \% \mathrm{CI} 1 \cdot 01,1 \cdot 32)$ but not in women $(\mathrm{RR}=$ $1 \cdot 08 ; 95 \%$ CI $0 \cdot 94,1 \cdot 24)$. After adjustment for carbohydrate intake, there was an overall significant inverse 
Table 2 Multivariate-adjusted relative risks (RR) by gender with $95 \% \mathrm{Cl}^{*}$ in parentheses (only for pooled RR across gender) for CVD (CHD and ischaemic stroke), for fruit and vegetable intake among men and women by carbohydrate intake: the Health Professionals' Follow-Up Study (HPFS) and the Nurses' Health Study (NHS)

\begin{tabular}{|c|c|c|c|c|c|c|c|}
\hline & & \multicolumn{6}{|c|}{ Percentage of energy from carbohydrate intake } \\
\hline & & \multicolumn{2}{|c|}{ Low $(<40 \%)$} & \multicolumn{2}{|c|}{ Moderate $(>40-55 \%)$} & \multicolumn{2}{|c|}{ High $(>55 \%)$} \\
\hline & & $\begin{array}{c}\text { RR for quintile } 5 \\
\text { v. quintile } 1\end{array}$ & RRt for trend & $\begin{array}{l}\text { RR for quintile } 5 \\
\text { v. quintile } 1\end{array}$ & $\mathrm{RR}+$ for trend & $\begin{array}{c}\text { RR for quintile } 5 \\
\text { v. quintile } 1\end{array}$ & $\mathrm{RR}$ t for trend \\
\hline \multirow[t]{3}{*}{ Total fruits and vegetables } & HPFS & $0 \cdot 60$ & $0 \cdot 74$ & 0.90 & 0.89 & $1 \cdot 22$ & $1 \cdot 04$ \\
\hline & NHS & 0.87 & 0.91 & 0.96 & 0.94 & $1 \cdot 20$ & 0.94 \\
\hline & Pooled & $0.73(0.51,1.04)$ & $0.81(0.65,1.01)$ & $0.95(0.89,1.02)$ & $0.92(0.82,1.02)$ & $1.21(0 \cdot 88,1 \cdot 65)$ & $1.00(0.83,1.20)$ \\
\hline \multirow{3}{*}{ Total fruits } & HPFS & 1.08 & 0.76 & 0.76 & 0.89 & $1 \cdot 19$ & 0.96 \\
\hline & NHS & $1 \cdot 14$ & 1.03 & $0 \cdot 86$ & 0.90 & $1 \cdot 30$ & $0 \cdot 89$ \\
\hline & Pooled & $1 \cdot 11(0.78,1 \cdot 58)$ & $0.88(0.66,1 \cdot 18)$ & $0.81(0.70,0.94) \ddagger$ & $0.90(0.80,1 \cdot 01)$ & $1.25(0.87,1.78)$ & $0.93(0.76,1.13)$ \\
\hline \multirow[t]{3}{*}{ Total vegetables } & HPFS & 0.81 & 0.75 & 0.95 & 0.94 & 1.04 & 1.05 \\
\hline & NHS & 0.94 & 0.91 & 0.91 & $1 \cdot 01$ & $0 \cdot 89$ & 0.92 \\
\hline & Pooled & $0.86(0.67,1.12)$ & $0.82(0.68,0.99) \ddagger$ & $0.93(0.81,1.07)$ & $0.97(0.88,1.06)$ & $0.96(0.74,1 \cdot 25)$ & $0.99(0.84,1.17)$ \\
\hline \multirow{3}{*}{ Total citrus fruit } & HPFS & 0.78 & 0.92 & 0.97 & 1.01 & 0.99 & 1.06 \\
\hline & NHS & 1.07 & 0.96 & 0.87 & 0.92 & $1 \cdot 13$ & 1.04 \\
\hline & Pooled & $0.92(0.67,1 \cdot 26)$ & $0.94(0.81,1.08)$ & $0.92(0.81,1.05)$ & $0.97(0.89,1.06)$ & $1.05(0.81,1.37)$ & $1.05(0.93,1.19)$ \\
\hline \multirow{3}{*}{ Citrus fruit juice } & HPFS & 0.91 & 1.00 & 0.97 & 0.97 & 1.27 & $1 \cdot 11$ \\
\hline & NHS & $1 \cdot 25$ & $1 \cdot 07$ & 0.95 & 0.92 & $1 \cdot 24$ & 1.02 \\
\hline & Pooled & $1.07(0.79,1.45)$ & $1 \cdot 03(0 \cdot 86,1 \cdot 23)$ & $0.96(0.85,1.09)$ & $0.95(0.87,1.04)$ & $1.25(0.98,1.61)$ & $1.07(0.91,1.26)$ \\
\hline \multirow[t]{3}{*}{ Cruciferous vegetables } & HPFS & $1 \cdot 10$ & 0.99 & 0.92 & 0.95 & 0.86 & 0.94 \\
\hline & NHS & 0.99 & $0 \cdot 87$ & $1 \cdot 20$ & 1.09 & 0.94 & 0.93 \\
\hline & Pooled & $1.05(0.83,1.34)$ & $0.94(0.73,1.21)$ & $1.05(0.91,1.36)$ & $1.01(0.88,1 \cdot 15)$ & $0.89(0.71,1 \cdot 13)$ & $0.94(0.73,1.20)$ \\
\hline \multirow[t]{3}{*}{ Green leafy vegetables } & HPFS & $0 \cdot 70$ & 0.78 & 0.87 & 0.89 & 0.95 & 1.00 \\
\hline & $\mathrm{NHS}$ & 0.83 & 0.90 & 0.83 & 0.91 & 0.90 & 0.96 \\
\hline & Pooled & $0.76(0.60,0.96) \ddagger$ & $0.84(0.71,0.99) \ddagger$ & $0.85(0.75,0.97) \ddagger$ & $0.90(0.82,0.99) \ddagger$ & $0.92(0 \cdot 72,1 \cdot 18)$ & $0.98(0.83,1.17)$ \\
\hline \multirow{3}{*}{ Carotene-rich fruits and vegetables } & HPFS & 0.86 & 0.89 & 0.97 & 0.96 & 0.86 & 0.99 \\
\hline & $\mathrm{NHS}$ & 0.95 & 0.92 & 0.90 & 0.96 & 0.82 & 0.96 \\
\hline & Pooled & $0.90(0.69,1 \cdot 17)$ & $0.90(0.81,0.99) \ddagger$ & $0.94(0.82,1.07)$ & $0.96(0.91,1.01)$ & $0.84(0.65,1.08)$ & $0.98(0.89,1.07)$ \\
\hline \multirow[t]{3}{*}{ Vitamin C-rich fruits and vegetables } & HPFS & 0.89 & 0.90 & 0.95 & 0.97 & 1.05 & 1.04 \\
\hline & NHS & 0.93 & 0.99 & 0.90 & 0.96 & $1 \cdot 11$ & $1 \cdot 01$ \\
\hline & Pooled & $0.91(0.68,1.21)$ & $0.94(0.85,1.05)$ & $0.92(0.81,1.06)$ & $0.96(0.91,1.01)$ & $1.08(0.82,1.43)$ & $1.03(0.94,1.13)$ \\
\hline \multirow[t]{3}{*}{ Legumes } & HPFS & 1.07 & $1 \cdot 08$ & 0.92 & 0.79 & 1.04 & 0.90 \\
\hline & NHS & $1 \cdot 34$ & $2 \cdot 83$ & $1 \cdot 06$ & $1 \cdot 21$ & $1 \cdot 22$ & $1 \cdot 29$ \\
\hline & Pooled & $1.19(0.93,1.53)$ & $1.69(0.66,4.32)$ & $0.98(0.86,1.12)$ & $0.96(0.63,1.44)$ & $1.13(0.88,1.44)$ & $1.01(0.67,1.53)$ \\
\hline \multirow[t]{3}{*}{ Potatoes } & HPFS & $1 \cdot 16$ & 1.09 & $1 \cdot 32$ & $1 \cdot 30$ & $1 \cdot 10$ & $1 \cdot 30$ \\
\hline & NHS & $1 \cdot 25$ & $1 \cdot 24$ & 0.99 & 1.03 & $1 \cdot 15$ & $1 \cdot 20$ \\
\hline & Pooled & $1.21(0.93,1.56)$ & $1.15(0.87,1.52)$ & $1.14(0.86,1.52)$ & $1.17(0.94,1.46) \ddagger$ & $1.12(0.86,1.47)$ & $1.26(0.93,1.69)$ \\
\hline
\end{tabular}

*Adjusted for total energy intake, whole grains (quintiles), age (5-year categories), smoking (never, past, current: 1-14, 15-24 and $>25$ cigarettes/d), alcohol (five categories), BMI (five categories), multivitamin and vitamin E supplement use, aspirin use, physical activity (five categories), family history of myocardial infarction (positive if either the mother or father had CHD at age 65 years or less in NHS or before age of 60 years in HPFS), history of hypertension, hypercholesterolaemia and incident diabetes, and, for women only, menopausal status and hormone replacement therapy.

tContinuous variable for increment of 5 servings/d for total fruit and vegetables, 3 servings/d for total fruits and total vegetables and 1 serving/d for others, using median values of deciles of intake.

$\ddagger P<0.05$ for comparing the extreme quintiles or for the test for trend as applicable.

Note: The test for homogeneity across gender was not significant for any of the comparisons. 
association between high fruit and vegetable intake and ischaemic CVD in men ( $\mathrm{RR}=0.90 ; 95 \% \mathrm{CI} 0 \cdot 82,0.99)$ but there was no significant association among women $(\mathrm{RR}=0.92 ; 95 \% \mathrm{CI} 0.83,1 \cdot 02)$; the association was significant when pooled across the two cohorts: $\mathrm{RR}=0 \cdot 91$ (95\% CI $0.85,0.98)$ (not shown in the table). In contrast, after adjustment for fruits and vegetables, there was no relationship between high carbohydrate intake and ischaemic CVD $(\mathrm{RR}=0.97$; $95 \%$ CI 0.87, 1.09 in men; $\mathrm{RR}=1 \cdot 00 ; 95 \% \mathrm{CI} 0 \cdot 90,1 \cdot 11$ in women; pooled $\mathrm{RR}=$ 0.99; $95 \%$ CI $0.92,1.07$; test for interaction $P=0.48$ for men, 0.52 for women and 0.60 for pooled).

\section{Discussion}

Total fruits and vegetables showed a small non-significant inverse association among men and women with low carbohydrate intake; there was no association among the moderate and high carbohydrate groups. There was a smaller inverse association for total vegetables (but not for total fruits) with increasing carbohydrate intake. Similar trends were seen for green leafy vegetables and carotene-rich fruits and vegetables. The analyses controlled for the major cardiovascular risk factors. However, we cannot exclude the possibility that the associations may reflect residual confounding by additional factors related to dietary selection.

The association between total fruits and citrus fruit intake and ischaemic CVD is modest in the present study. Our previous publications from the same populations with shorter follow-up showed significant inverse associations between total fruit, citrus fruit and citrus fruit juice with ischaemic stroke ${ }^{(2)}$, but less with $\mathrm{CHD}^{(3)}$. In the present study, we combined CHD and ischaemic stroke and we found a weaker association, because the majority of cases were CHD. Since fruit and vegetable intake is self-reported, there is an inherent limitation in the accuracy of these data. We have found the validity of our FFQ to be good for both fruits and vegetables ${ }^{(11,12)}$. However, some misclassification of diet is unavoidable, and the non-differential misclassification would likely bias the associations towards the null. Because of the prospective design where diet was assessed prior to the occurrence of CVD, the ascertainment of diet was unlikely to be biased with respect to cardiovascular outcomes. Also, given our high socio-economic population, fruit and vegetable intake is on average higher in our cohort than in the general population. Hence, stronger effects seen at lower thresholds of intake could be missed.

The lack of association between total carbohydrate intake and CVD is consistent with our previous publications, which suggest that it is the form of carbohydrate rather than total carbohydrate intake which is important ${ }^{(20,21)}$. In a recent publication, a lower risk of CHD was seen only among women with low carbohydrate intake who consumed vegetable sources of fat and protein, but not among those consuming animal sources of fat and protein ${ }^{(22)}$. Although low-carbohydrate diets have been gaining popularity in recent years ${ }^{(23,24)}$, we were not able to capture the very low carbohydrate group in the present analysis. In our populations, energy-adjusted carbohydrate intake in fact showed a small increase over time in both cohorts. There were no consistent trends over time in intake of fruits, vegetables, green leafy vegetables, citrus fruit and energy-adjusted vitamin C. Fruit intake was strongly associated, but vegetables showed a very small correlation with carbohydrate intake over time. As expected, with increasing carbohydrate intake, there was an increase in whole grains but a much smaller increase in dietary and cereal fibre. The data for the present study spanned from 1984 to 2000 , which was prior to the escalation in popularity of low-carbohydrate diets. Also, our population included health professionals, who may be less likely to adopt radically low carbohydrate diets. We still saw a lower intake of fruits and vegetables in the low carbohydrate intake group, which might probably be due to a low-carbohydrate high-fat diet being the less 'healthy' diet of the 1990s, as most behavioural risk factors were worse in the low carbohydrate group. In other words, because of the widespread recommendations about low-fat diets, people who consumed such diets tended to be more health-conscious and adapted a healthier lifestyle.

In conclusion, total fruit and vegetable intake was inversely associated with ischaemic CVD among persons with low carbohydrate intake. The inverse association was due primarily to vegetable intake. As consumption of fruits and vegetables also tended to be lower among those choosing low-carbohydrate diets, maintaining a daily consumption of at least 5 servings in this group would be important.

\section{Acknowledgements}

We are indebted to the participants of the Health Professionals' Follow-Up and Nurses' Health Studies for their continued cooperation and participation; to Al Wing, Mira Kaufman, Karen Corsano, Marcia Goetsch and Sona Tumanyan for computer assistance; to Jill Arnold, Betsy Frost-Hawes, Kerry Demers, Mitzi Wolff, Gary Chase and Barbara Egan for their assistance in the compilation of data; and to Laura Sampson for maintaining our food composition tables.

Conflicts of interest: There were no conflicts of interest.

Financial support: The present research was supported by grants HL34595, HL35464, CA40356, CA55075 and the Florida Department of Citrus.

Author contributions: K.J.J. - contribution to analysis of data, interpretation and writing of the manuscript; 
H.-C.H. - analysis and interpretation; T.Y.L. - analysis and interpretation of the data; F.B.H. - analysis and interpretation of the data; E.B.R. - analysis and interpretation, collection of data; M.J.S. - analysis and interpretation, collection of data; G.C. - analysis and interpretation, collection of data; W.C.W. - analysis and interpretation, collection of data.

\section{References}

1. Atkins RC (1998) Dr. Atkins New Diet Revolution. New York: Avon Books.

2. Joshipura KJ, Ascherio A, Manson JE, Stampfer MJ, Rimm EB, Speizer FE, Hennekens CH, Spiegelman D \& Willett WC (1999) Fruit and vegetable intake in relation to risk of ischemic stroke. JAMA 282, 1233-1239.

3. Joshipura KJ, Hu FB, Manson JE et al. (2001) The effect of fruit and vegetable intake on risk for coronary heart disease. Ann Intern Med 134, 1106-1114.

4. Hung $\mathrm{HC}$, Joshipura $\mathrm{KJ}$, Jiang $\mathrm{R}, \mathrm{Hu} \mathrm{FB}$, Hunter $\mathrm{D}$, Smith-Warner SA, Colditz GA, Rosner B, Spiegelman D \& Willett WC (2004) Fruit and vegetable intake and risk of major chronic disease. J Natl Cancer Inst 96, 1577-1584.

5. Knekt P, Reunanen A, Jarvinen R, Seppanen R, Heliovaara M \& Aromaa A (1994) Antioxidant vitamin intake and coronary mortality in a longitudinal population study. Am J Epidemiol 139, 1180-1189.

6. Rimm EB, Stampfer MJ, Ascherio A, Giovannucci E, Colditz GA \& Willett WC (1993) Vitamin E consumption and the risk of coronary heart disease in men. $N$ Engl $J$ Med 328, $1450-1456$.

7. Khaw KT \& Barrett-Connor E (1987) Dietary potassium and stroke-associated mortality. A 12 -year prospective population study. $N$ Engl J Med 316, 235-240.

8. Knekt P, Jarvinen R, Reunanen A \& Maatela J (1996) Flavonoid intake and coronary mortality in Finland: a cohort study. BMJ 312, 478-481.

9. Rimm EB, Ascherio A, Giovannucci E, Spiegelman D, Stampfer MJ \& Willett WC (1996) Vegetable, fruit, and cereal fiber intake and risk of coronary heart disease among men. JAMA 275, 447-451.

10. Curb JD, Masaki K, Rodriguez BL, Abbott RD, Burchfiel CM, Chen R, Petrovitch H, Sharp D \& Yano K (1996) Peripheral artery disease and cardiovascular risk factors in the elderly. The Honolulu Heart Program. Arterioscler Thromb Vasc Biol 16, 1495-1500.

11. Feskanich D, Rimm EB, Giovannucci EL, Colditz GA, Stampfer MJ, Litin LB \& Willett WC (1993) Reproducibility and validity of food intake measurements from a semiquantitative food frequency questionnaire. J Am Diet Assoc 93, 790-796.

12. Rimm EB, Giovannucci EL, Stampfer MJ, Colditz GA, Litin LB \& Willett WC (1992) Reproducibility and validity of an expanded self-administered semiquantitative food frequency questionnaire among male health professionals. Am J Epidemiol 135, 1114-1126.

13. Salvini S, Hunter DJ, Sampson L, Stampfer MJ, Colditz GA, Rosner B \& Willett WC (1989) Food-based validation of a dietary questionnaire: the effects of week-to-week variation in food consumption. Int $J$ Epidemiol 18, 858-867.

14. Feskanich D, Ziegler RG, Michaud DS, Giovannucci EL, Speizer FE, Willett WC \& Colditz GA (2000) Prospective study of fruit and vegetable consumption and risk of lung cancer among men and women. J Natl Cancer Inst 92, 1812-1823.

15. Caan B, Hiatt RA \& Owen AM (1991) Mailed dietary surveys: response rates, error rates, and the effect of omitted food items on nutrient values. Epidemiology 2, 430-436.

16. Hu FB, Stampfer MJ, Rimm E, Ascherio A, Rosner BA, Spiegelman D \& Willett WC (1999) Dietary fat and coronary heart disease: a comparison of approaches for adjusting for total energy intake and modeling repeated dietary measurements. Am J Epidemiol 149, 531-540.

17. DerSimonian R \& Laird N (1986) Meta-analysis in clinical trials. Control Clin Trials 7, 177-188.

18. Willett W (1998) Nutritional Epidemiology. New York: Oxford University Press.

19. Hu FB, Stampfer MJ, Manson JE, Rimm E, Colditz GA, Rosner BA, Hennekens CH \& Willett WC (1997) Dietary fat intake and the risk of coronary heart disease in women. $N$ Engl J Med 337, 1491-1499.

20. Liu S, Willett WC, Stampfer MJ, Hu FB, Franz M, Sampson L, Hennekens CH \& Manson JE (2000) A prospective study of dietary glycemic load, carbohydrate intake, and risk of coronary heart disease in US women. Am J Clin Nutr $\mathbf{7 1}$, $1455-1461$.

21. Fung TT, Stampfer MJ, Manson JE, Rexrode KM, Willett WC \& Hu FB (2004) Prospective study of major dietary patterns and stroke risk in women. Stroke 35, 2014-2019.

22. Halton TL, Willett WC, Liu S, Manson JE, Albert CM, Rexrode K \& Hu FB (2006) Low-carbohydrate-diet score and the risk of coronary heart disease in women. $N$ Engl J Med 355, 1991-2002.

23. Dansinger ML, Gleason JA, Griffith JL, Selker HP \& Schaefer EJ (2005) Comparison of the Atkins, Ornish, Weight Watchers, and Zone diets for weight loss and heart disease risk reduction: a randomized trial. JAMA 293, $43-53$.

24. Volpe SL (2006) Popular weight reduction diets. J Cardiovasc Nurs 21, 34-39. 